\title{
SOSIALISASI BAHAYA HIPOKINETIK TERHADAP PERTUMBUHAN DAN PERKEMBANGAN ANAK PADA GURU PJOK SD DAN SMP SE- KECAMATAN CIBEREUM KOTA TASIKMALAYA
}

\author{
Melya Nur Herliana1, Budi Indrawan², Iman Rubiana ${ }^{3}$ \\ 1, 3, 3 Universitas Siliwangi
}

melya.nh22@unsil.ac.id¹, budiindrawan@unsil.ac.id²,imanrubiana@unsil.ac.id²

\begin{abstract}
ABSTRAK
Tujuan pengabdian ini adalah meningkatkan pengentahuan Guru PJOK SMP dan SD di lingkungan MGMP dan KKG PJOK Kecamatan Cibereum Kota Tasikmalaya dalam mengetahui tentang bahaya dari penyakit Hipokinetik (kurang gerak) terhadapa pertumbuhan dan perkembangan anak/peserta didik. Peserta pengabdian ini adalah guru pjok SMP dan SD yang tergabung dalam MGMP dan KKG PJOK Kota Tasikmalaya yang berjumlah 45 orang. Guru PJOK SMP sebanyak 20 orang dan 25 orang guru PJOK SD. Setelah diberikan sosialisasi tentang bahaya dari hipokinetik diharapkan para guru bisa memberikan informasi terhadap peserta didik tentang bahaya hipokinetik dan bisa memberikan pengajaran yang mampu meningkatkan motivasi siswa dalam melakukan aktivitas aktif. Guru juga diharapkan mampu memberikan informasi tentang pencegahan dari bahaya hipokinetik
\end{abstract}

Kata kunci : hipokinetik, pertumbuhan, perkembangn

\begin{abstract}
The purpose of this service is to increase the awareness of Teachers of Junior and Elementary School PJOK in the MGMP and PJOK KKG Cibereum District of Tasikmalaya City in knowing about the dangers of hypokinetics (lack of movement) on the growth and development of children / students. Participants in this service are junior and elementary school corner teachers who are members of the MGMP and KKOK of Tasikmalaya City KKG totaling 45 people. The PJOK junior high school teacher is 20 people and 25 elementary school PJOK teachers. After being given socialization about the dangers of hypokinetics, it is expected that the teachers can provide information to students about the dangers of hypokinetics and can provide teaching that can increase students' motivation in active activities. Teachers are also expected to be able to provide information about prevention from the dangers of hypokinetics.
\end{abstract}

Keywords: hypokinetics, growth, development

\section{A. PENDAhUluan}

Melihat masa lalu penuh dengan aktivitas yang dilakukan menjadikan pertumbuhan dan perkembangan terutama dalam segi fisik sangat meningkat dan bermanfaat untuk masa sekarang. Contoh seorang kakek yang berusia sekitar 60 tahun yang masih mampu bekerja disawah, seorang bapak usia 50 tahun masih bisa melakukan aktivitas fisik dengan bersepeda dan bermain bulu tangkis, Hal tersebut pengaruh dari aktivitas yang dilakukan pada masa usia dini.

Berbeda dengan masa sekarang dimana kemajuan teknologi pada saat ini seakan membuat pertumbuhan dan perkembangan menjadi terhambat. Namun bukan karena 
adanya teknologi saja yang menjadi faktor penghambatnya, tetapi dikarenakan manusianya yang menginginkan teknologi menjadi alat bantu untuk mengefesiensikan pekerjaan. Terutama berbagai pekerjaan yang harus membutuhkan aktivitas gerak.

Contoh yang terjadi apabila kita berpergian kepusat pembelanjaan kita pasti memilih ekskalator dibandingkan dengan menaiki tangga, memindahkan chanel tv menggunakan remot, berpergian kesekolah menggunakan sepedah motor atau mobil, lebih asyik bermain handphone dibandingkan dengan bermain aktivitas fisik dengan teman sebaya, dan banyak hal lainnya. Hal ini akan menjadikan pertumbuhan dan perkembangan gerak anak akan menjadi terhambat.

Pertumbuhan dan perkembangan merupakan sebuah istilah ilmu yang mempunyai pengertian yang berbeda, namun keduanya memiliki keterkaitan yang sangat erat bahkan tidak dapat dipisahkan antara satu dengan yang lainnya. Pertumbuhan merupakan proses kuantitatif yang menunjukkan perubahan yang dapat diamati secara fisik. Selanjutnya pertumbuhan diamati melalui penimbangan berat badan, pengukuran tinggi badan, lingkar kepala dan sebagainya. Sementara itu, perkembangan merupakan proses kualitatif yang menunjukkan bertambahnya kemampuan (keterampilan) dalam struktur dan fungsi tubuh yang lebih kompleks dalam pola yang beraturan dan dapat diramalkan sebagai hasil proses pematangan (SADAM, 2017)

Dalam artikel Psikologi Perkembangan yang ditulis oleh Syaodih (2017) menyatakan bahwa "Seorang ahli lain bernama Froebel (Roopnaire, J.L \& Johnson, J.E., 1993) mengungkapkan bahwa masa anak merupakan suatu fase yang sangat penting dan berharga, dan merupakan masa pembentukan dalam periode kehidupan manusia. Oleh karenanya masa anak sering dipandang sebagai masa emas (golden age) bagi penyelenggaraan pendidikan. Masa anak merupakan fase yang sangat fundamental bagi perkembangan individu karena pada fase inilah terjadinya peluang yang sangat besar untuk pembentukan dan pengembangan pribadi seseorang. Menurut Froebel, jika orang dewasa mampu menyediakan suatu "taman" yang dirancang sesuai dengan potensi dan bawaan anak, maka anak akan berkembang secara wajar". Menurut Permana, Dhias (2013, 25) dalam artikel ilmiah menyatakan bahwa "Kemampuan perkembangan motorik kasar diawali dengan koordinasi tubuh, duduk, merangkak, berdiri, dan diakhiri dengan berjalan. 
Kemampuan perkembangan gerak motorik kasar ini ditentukan oleh perkembangan kekuatan otot, tulang, dan koordinasi otot untuk menjaga keseimbangan tubuh. Perkembangan motorik kasar tidak hanya dipengaruhi oleh kemampuan fisik, tetapi juga kesiapan psikis anak untuk melakukannya seperti memanjat, dan berlari. Kemampuan motorik kasar sangat berpengaruh pada perkembangan anak. Bila mengalami keterlambatan pada kemampuan motorik, maka anak akan mengalami keterlambatan perkembangan dan pertumbuhan anak". Jadi pertumbuhan dan perkembangan diawali dari mulai masa anak. Oleh karena itu sudah menjadi tugas kita bersama untuk mampu memberikan motivasi atau perlakuan kepada anak agar pada masa tersebut anak bisa berkembang secara stabil dan baik.

Perkembangan berkenaan dengan keseluruhan kepribadian individu karena kepribadian individu membentuk suatu kesatuan yang terintegrasi. Secara sederhana, aspek utama kepribadian dapat dibedakan sebagai berikut: aspek fisik motorik, aspek intelektual, aspek sosial, aspek bahasa, aspek moral, dan aspek keagamaan. Melihat dari pengertian yang telah dikemukakan bahwa pertumbuhan dan perkembangan sangatlah penting bagi kehidupan manusia. Permasalahan terjadi sekarang ini pertumbuhan dan perkembangan gerak pada anak usia dini yang mana pertumbuhan dan perkembangannya harus melewati beberapa fase namun pada kenyataanya banyak fase terlewati dikarenakan kemajuan teknologi yang tidak diimbangan dengan pengetahuan mengenai pertumbuhan dan perkembangan gerak anak usia dini yang mengakibatkan timbulah penyakit yang disebut dengan penyakit Hipokinetik.

Hipokinetik adalah kondisi kurang bergerak seperti penggunaan remote control, komputer, lift dan tangga berjalan, tanpa dimbangi dengan aktifitas fisik yang akan menimbulkan penyakit akibat kurang gerak (Rebanas, 2015). Penyakit hipokinetik merupakan penyakit yang berhubungan dengan kurang gerak (inacitvity) atau gaya hidup sedenter (sedentary). Kehidupan sehari-hari yang kurang aktif bergerak atau berolahraga menjadi faktor risiko terjadinya penyakit hipokinetik (Bustan, 2011). Karena itu, keadaan hipokinetik ini disebut juga penyakit perilaku (behavioral diseases). Selain itu, penyakit ini berlangsung secara menahun atau mempunyai "masa inkubasi" (masa laten) yang panjang sehingga termasuk ke dalam penyakit kronik. Dari segi penyebab 
biologis/mikroorganisma, penyakit ini bukan disebabkan oleh kuman penyakit dan tidak menular sehingga disebut juga penyakit tidak menular (non-communicable disease).

Adapun penyakit yang tergolong dalam penyakit hipokinetik adalah berbagai penyakit kronik yang berkaitan dengan pola hidup kurang aktif, di dalamnya termasuk kegemukan, diabetes mellitus, hipertensi, penyakit jantung, strok, osteoporosis, osteoarthritis, dan kanker. Penyakit-penyakit ini timbul sehubungan dengan gaya hidup, disertai dengan berbagai faktor risiko lainnya yang sesuai dengan masing-masing penyakit. Penyakit hipokinetik terjadi karena gaya hidup yang kurang gerak, namun pola sedenter ini bukan satu-satunya penyebab keadaan ini. Berbagai faktor yang mendukung terjadinya penyakit ini disebut sebagai faktor risiko yang terdiri atas berbagai faktor atau faktor ganda (multiple factors) yang meningkatkan kemungkinan risiko terjadinya penyakit hipokinetik. Penyakit hipokinetik ini mempunyai faktor risikonya masing-masing, selain faktor sendeter itu sendiri .

Penyakit hipokinetik pada anak usia dini dapat diminimalisir dengan mengetahui tentang fase-fase pertumbuhan dan perkembangan gerak (motorik) anak pada usiannya. perkembangan gerak (motorik) adalah proses tumbuh kembang kemampuan gerak seorang anak. Pada dasarnya, perkembangan ini berkembang sejalan dengan kematangan saraf dan otot anak. Sehingga, setiap gerakan sesederhana apapun, adalah merupakan hasil pola interaksi yang kompleks dari berbagai bagian dan system dalam tubuh yang dikontrol oleh otak. Dengan permasalahan ini maka kami dosen pengajar Program Studi Pendidikan Jasmani Fakultas Keguruan dan Ilmu Pendidikan Universitas Siliwangi Tasikmalaya ingin melakukan sosialisasi mengenai pentingnya pertumbuhan dan perkembangan bagi anak dengan cara melakukan aktivitas aktif, mengenai bahaya dan dampak dari hipokinetik terhadap pertumbuhan dan perkembangan anak dan Memberikan pemahaman mengenai pencegahan dari bahaya hipokinetik bagi pertumbuhan dan perkembangan anak.

\section{B. LANDASAN TEORI}

Pentingnya pengetahuan tentang pertumbuhan dan perkembangan terhadap anak. Dengan tumbuh kembang yang baik anak akan mempunyai derajat sehat yang baik dari mulai pertumbuhan secara fisik dan perkembangan secara psikologis. Sejalan dengan 
pendapat Sumantri, Mulyani (2015) dalam modul Pertumbuhan dan perkembangan anak menyatakan bahwa pentingnya mengetahui fase-fase tentang pertumbuhan dan perkembangan anak.

Pertama, kita akan mempunyai ekspektasi yang nyata tentang anak dan remaja. Dari psikologi perkembangan akan diketahui pada umur berapa anak mulai berbicara dan mulai mampu berpikir abstrak. Halhal itu merupakan gambaran umum yang terjadi pada kebanyakan anak, di samping itu akan diketahui pula pada umur berapa anak tertentu akan memperoleh keterampilan perilaku dan emosi khusus. Kedua, pengetahuan tentang psikologi perkembangan anak membantu kita untuk merespon sebagaimana mestinya pada perilaku tertentu dari seorang anak. Bila seorang anak dari Taman Kanak-kanak tidak mau sekolah lagi karena diganggu temannya, apa yang harus dilakukan oleh guru dan orang tuanya? Bila anak selalu ingin merebut mainan temannya apakah dibiarkan saja? Psikologi perkembangan akan membantu menjawab pertanyaan-pertanyaan itu dan menunjukkan sumber-sumber jawaban serta pola-pola anak mengenai pikiran, perasaan, dan perilakunya. Ketiga, pengetahuan tentang perkembangan anak akan membantu mengenali berbagai penyimpangan dari perkembangan yang normal. Bila anak umur dua tahun belum berceloteh (banyak bicara) apakah dokter dan guru harus mengkhawatirkannya? Bagaimana bila hal itu terjadi pada anak umur tiga atau empat tahun? Apa yang perlu dilakukan bila remaja umur lima belas tahun tidak mau lagi sekolah karena keinginannya yang berlebihan yaitu ingin melakukan sesuatu yang menunjukkan sikap "jagoan"? Jawaban akan lebih mudah diperoleh apabila kita mengetahui apa yang biasanya terjadi pada anak atau remaja. Keempat, dengan mempelajari perkembangan anak akan membantu memahami diri sendiri.

Namun saat ini perkembangan dan pertumbuhan anak sedikitnya terhambat dilihat dari aktivitas yang dilakukan lebih banyak melakukan aktivitas secara pasif dikarenakan anak lebih senang duduk dengan bermain game. Dengan hal ini dikwahatirkan anak akan terserang penyakit kurang gerak atau dengan kata lain penyakit Hipokinetik. Hipokinetik adalah kondisi kurang bergerak seperti penggunaan remote control, komputer, lift dan tangga berjalan, tanpa dimbangi dengan aktifitas fisik yang akan menimbulkan penyakit akibat kurang gerak. Adapun penyakit yang tergolong dalam penyakit hipokinetik adalah 
berbagai penyakit kronik yang berkaitan dengan pola hidup kurang aktif, di dalamnya termasuk kegemukan, diabetes mellitus, hipertensi, penyakit jantung, strok, osteoporosis, osteoarthritis, dan kanker. Menurut Junaidi, Said $(2011,5)$ dalam artikelnya menyatakan bahwa Pada manusia yang sudah berusia lanjut, penyakit akibat kurang gerak ini akan berakibat pada tidak berdayanya lansia baik pada sisi fisik, mental, sosial dan finansial.

Maka dengan hal ini guru pendidikan jasmani harus mengetahui ilmu pengetahuan tentang pertumbuhan dan perkembangan anak. Dengan ilmu pengetahuan pertumbuhan dan perkembangan anak guru diharapkan mampu memberikan rangsangan terhadap anak/peserta didik agar selalu melakukan aktivitas fisik secara aktif dengan seimbangan agar anak mempunyai pertumbuhan dan perkembangan dengan baik dan anak akan terhidar dari penyakit kurang gerak/ hipokinetik.

\section{METODE PELAKSANAAN}

Pada mitra yaitu guru PJOK SMP dan SD dalam ruang lingkup MGMP dan KKG Kecamatan Cibereum Kota Tasikmalaya, masih terdapat beberapa masalah yang menjadi kendala. Masalah tersebut adalah

1. Guru olahraga belum mengetahui tentang bahaya dari hipokinetik.

2. Bahaya hipokinetik terhadap pertumbuhan dan perkembangan anak.

3. Informasi mengenai pencegahan dari bahaya hipokinetik.

Dasar dari permasalahan yang terjadi dengan ini Tim pengembangan melakukan koordinasi dan diskusi untuk bisa memecahkan permasalahan - permasalahan yang terjadi. Maka dilakukan sosialisasi tentang bahaya hipokinetik terhadap guru PJOK SMP dan SD dalam ruang lingkup MGMP dan KKG Kecamatan Cibereum Kota Tasikmalaya. Dalam sosialisasi pertama pemateri menjelaskan terlebih dahulu tentang pentingnya pertumbuhan dan perkembangan anak, menjelaskan tentang faktor-faktor yang mendukung terhadaa pertumbuhan dan perkembangan anak, terus pemateri menjelaskan tentang bahaya penyakit hipokinetik. Dalam sosialisasi terdapat diskusi atau Tanya jawab antara pemateri dengan peserta agar pengetahuan tentang bahayanya penyakit hipokinetik bisa dipahami dan dicemarmati oleh para peserta. 


\section{HASIL DAN PEMBAHASAN}

\section{Hasil}

Kegiatan sosialisasi yang sudah dilaksanakan sebanyak 2 kali pertemuan dengan pembahasan pada masing-masing MGMP PJOK SMP dan KKG SD. Lengkapnya bisa dilihat pada tabel di bawah ini.

Tabel 1. Kegiatan Sosialisasi Bahaya Hipokinetik

\begin{tabular}{|c|c|c|}
\hline No & Nama Kegiatan & Waktu Pelaksanaan \\
\hline 1. & $\begin{array}{c}\text { Pelaksanaan sosialisasi di MGMP PJOK SMP } \\
\text { Kecamatan Cibereum Kota Tasikmalaya }\end{array}$ & 24 Agustus 2018 \\
\hline 2. & $\begin{array}{c}\text { Pelaksanaan sosialisasi di KKG PJOK SD } \\
\text { Kecamatan Cibererum Kota Tasikmalaya }\end{array}$ & 25 Agustus 2018 \\
\hline
\end{tabular}
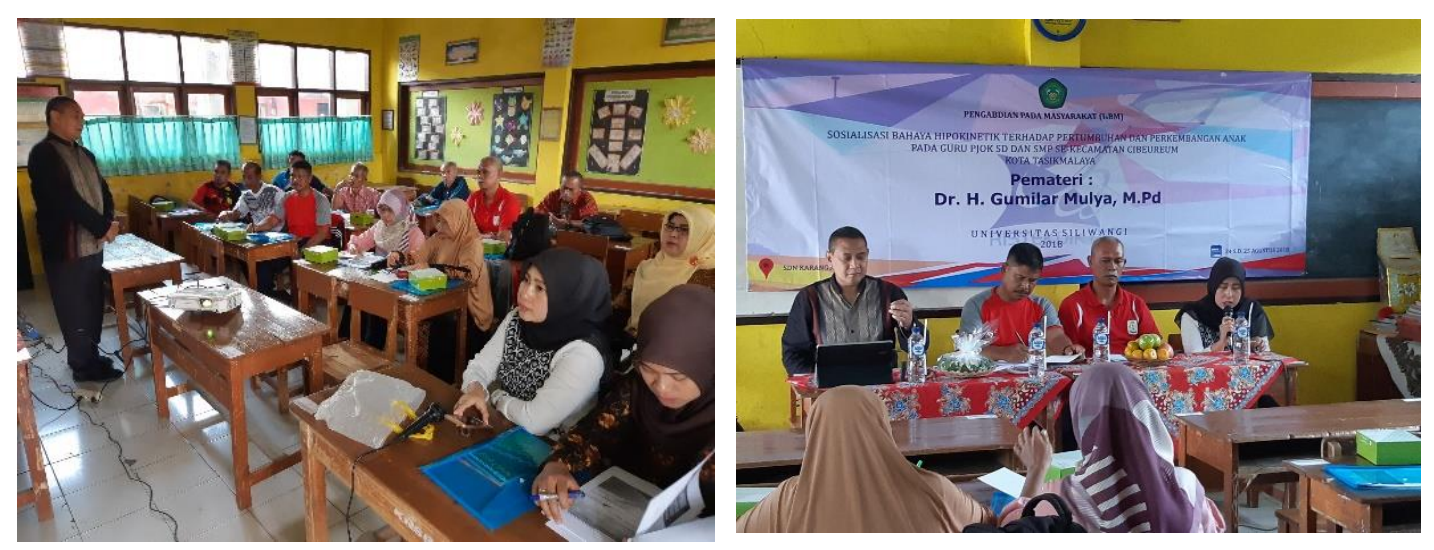

Gambar 1. Kegiatan pengabdian masyarakat

\section{Pembahasan}

Dengan sudah dilaksanakannya 2 sosialisasi dari bahaya hipokinetik pada guru PJOK SMP ddan SD dalam ruang lingkup MGMP PJOK SMP dan SD. Maka para guru PJOK bisa memberikan informasi dan pencegahan terhadap peserta didik tentang bahaya hipoinetik. Pemahaman tentang program bahaya hipokinetik menjadi salah satu bagian penting dalam mengembangkan dan menyadarkan guru terhadap siswanya. Dan diharapkan dengan semakin meluasnya kesadaran anak didik, akan mendorong adanya kesadaran terhadap keluarga melalui pendekatan komunikasi dari personal ke personal. Dengan demikian, proses pendidikan terhadap kesadaran bahaya hipokinetik dapat dikembangkan secara luas dan merata di berbagai lapisan masyarakat. Hal ini karena proses pendidikan yang ada 
merupakan salah satu program umum untuk membangun kehidupan masyarakat yang lebih baik. Dan dengan kesadaran yang lebih luas, diharapkan dapat mendorong pembangunan kualitas kehidupan masyarakat yang lebih baik. Sesuai dengan tanggung jawab yang melekat pada perguruan tinggi. Kesadaran masyarakat menjadi salah satu upaya dalam mengembangkan program yang lebih luas di masa yang akan datang, terutama dengan visi pembangunan masyarakat Indonesia pada tahun 2045.

\section{E. KESIMPULAN}

Rangkaian kegiatan IbBm berupa, "Sosialisasi Bahaya Hipokinetik Terhadap Pertumbuhan Dan Perkembangan Anak Pada Guru PJOK SD Dan SMP Se- Kecamatan Cibereum Kota Tasikmalaya" Terbukti dengan banyaknya masukan berupa pertanyaan maupun pendapat yang muncul ketika melakukan sosialisasi. Diharapkan kegiatan IbBM berupa, “Sosialisasi Bahaya Hipokinetik Terhadap Pertumbuhan Dan Perkembangan Anak Pada Guru PJOK SD Dan SMP Se- Kecamatan Cibereum Kota Tasikmalaya", tidak hanya dilakukan hanya sekali saja, melainkan harus dilakukan secara berkesinambungan dan dilakukan setiap Kecamatan di Kota Tasikmalaya.

\section{F. DAFTAR PUSTAKA}

Bustan. (2011). PENYAKIT HIPOKINETIK. Retrieved from http://bustansportscience.blogspot.com/2011/04/penyakit-hipokinetik.html

Junaidi, S. (2011). Pembinaan Fisik Lansia melalui Aktivitas Olahraga Jalan Kaki. Jurnal Media Ilmu Keolahragaan Indonesia, 1(1), 17-21.

Permana, D. F. W. (2013). Perkembangan Keseimbangan pada Anak Usia 7 s / d 12 Tahun Ditinjau dari Jenis Kelamin. Jurnal Media Ilmu Keolahragaan Indonesia, 3(1), 25-29.

Rebanas. (2015). Arti Kata "Hipokinetik." Retrieved from http://206.189.83.49/kamus/kesehatan/hipokinetik

SADAM. (2017). TEORI PERTUMBAHAN DAN PERKEMBANGAN JASMANI DAN GERAK. Retrieved from http://saddamdewana.blogspot.com/2016/01/teori-pembelajranpertumbuhan-dan_11.html

Sumantri, M. (2015). Pertumbuhan dan Perkembangan Anak. In PERTUMBUHAN DAN PERKEMBANGAN (pp. 1-52).

Syaodih, E. (2017). PSIKOLOGI PERKEMBANGAN. Retrieved from https://www.philogos.net/2017/06/psikologi-perkembangan-dr-ernawulan.html 